\section{Fossil Mammals}

Early Mammals. Edited by D. M. Kermack and K. A. Kermack. (Supplement to the Zoological Journal of the Linnean Society.) (V.50.) Pp. xiv +203. (Academic: New York and London, September 1971.) £5.30 ; $\$ 15.50$.

The Age of Mammals. By Bjorn Kurten. Pp. 250. (Weidenfeld and Nicolson: London, October 1971.) £3.50.

Mammals had already passed through two-thirds of their evolutionary history before the so called Age of Mammals began, but knowledge of the Mesozoic mammals is very scanty. In recent years, however, there has been a considerable revival of interest, stimulated by the discovery of new material, and the study of Mesozoic mammals is now one of the main growing-points of vertebrate palaeontology. Early Mammals is a collection of papers given at a symposium arranged by the Linnean Society in June 1970. It provides an excellent survey of the state of knowledge at that date, and should be useful to students as well as to research workers.

In view of the nature of the fossil material it is natural that most of the papers are concerned with teeth and jaws. J. A. Hopson describes the replacement of the teeth in the cynodont Diademodon and discusses the origin of the mammalian system of tooth-replacement ; R. G. Every and W. G. Kühne interpret wear-facets on teeth in terms of "thegosis", a mechanism of sharpening the cutting edges; A. W. Crompton interprets the same facets in terms of occlusal relations, in a well illustrated discussion of the origin of the tribosphenic molar. Other papers describe new material, again consisting of jaws and teeth: J. R. E. Mills on the teeth of Morganucodon, B. Krebs on dryolestid mandibles from Portugal, W. A. Clemens and P. M. Lees on Early Cretaceous mammals from England, B. H. Slaughter on Albian mammals from Texas and R. C. Fox on Campanian mammals from Alberta. Only one paper deals with any aspect of skull structure: this is by $\mathbf{K}$. A. Kermack and Z. Kielan-Jaworowska, who compare the brain cases of recently discovered Mongolian Cretaceous multituberculates with those of Morganucodon and the present-day monotremes. It is a pity that it was not possible to include at least a preliminary description of the skull and skeleton of Morganucodon, which have been under study for some years. In an interesting paper W. A. Clemens speculates on ecological and zoogeographical aspects of mammalian evolution in the Cretaceous, including the yet unsolved problem of how marsupials got into
Australia. Finally, G. G. Simpson, whose monographs of 1928-29 form the foundation of all subsequent work on Mesozoic mammals, gives a valuable critical survey of this developing field.

Only when we reach the Cainozoic does it become possible with some degree of confidence to visualize the mammals as living animals. In The Age of Mammals this is what Dr Kurten has set out to do. Writing in a very readable style, and avoiding technical terms as far as possible, he deals in turn with each epoch, describing the geography, climate and vegetation, together with the principal deposits in which fossil mammals occur. Stratigraphical correlation tables and palaeogeographical maps are provided. Against this background the mammals are described in sufficient detail to fit them into their environment. The reader is given a vivid impression of the successive phases of mammalian evolution during the past sixty-five million years, and an indication of the nature of the evidence on which the story is based. Some of the more interesting birds and reptiles are also treated. The book is well illustrated by sixty-seven line drawings and eleven plates by Margaret Lambert depicting life reconstructions of a wide range of fossil forms.

The Age of Mammals is not a textbook but an imaginative synthesis which should provide valuable background reading for students of zoogeography and mammalogy as well as vertebrate palaeontology. As a synthesis it also has interest for the specialist, though inevitably he would disagree with some of the details. There are occasions when the author allows his imagination to run rather far from the evidence: because the teeth of Planetotherium resemble those of the modern colugo it does not follow that it was a glider. The list of references is rather short, and there are several instances where one is left to guess at the source of information. While applauding the attempt to avoid technical terms, the use of unfamiliar English names for fossil groups sometimes leads to obscurity: for example, the term "thunderbird" is introduced on p. 171 , but not till p. 183 is it revealed that the author means the Phorushacidae. Another minor criticism is that the palaeogeographical maps do not always agree in detail with the descriptions in the text.

Nevertheless, Dr Kurten has succeeded in making the fossils live again. The book is full of vivid images: we can see herds of palaeotheres visiting their selected water-holes, a pantodont defending itself with its heavy paws, a mammoth using its curved tusks to scrape the snow off grass. Whether these things really happened we do not know, but we do know that fossils were once living animals. Anyone who thinks that palaeontology is a dull, mindnarrowing subject ought to read this book. P. M. Butler

\section{Anti-antibodies}

Human Anti-human Gamma-Globulins: Their Specificity and Function. (Proceedings held in Lund, October 1969.) Edited by R. Grubb and G. Samuelsson. Pp. xiit227. (Pergamon: Oxford, September 1971.) $£ 6.00$.

IN recent years, immunologists and geneticists have come to rely heavily on the properties of anti-antibodies. Studies of inheritance of genetic markers of immunoglobulin molecules, synthesis of these proteins at cellular level and the phenomenon of allotype suppression induced in rabbits and mice treated during foetal or perinatal life are all based on the use of anti-antibodies. This book, however, contains only a few papers dealing with these topics; the chief concern of the symposium held in Lund was the discussion of the origin, function and effect of anti-antibodies. Whether this aim was achieved during the meeting, and also whether the participants found the discussion informative, is difficult to say. In my view, however, the published proceedings fail to provide the reader with much valuable information. One reason is that the majority of the papers published in the book are "in abstract form only, as most of the work is already in the process of publication elsewhere". This means that out of the five papers included in session 5 dealing with the presence of immunoglobulin molecules on the surface of lymphocytes, three are no more than two pages long and the results have already been published in extenso in scientific journals. One of the few long papers published in the book also appeared recently in an immunological journal.

I was particularly disappointed to notice that the special lecture under the intriguing title of "Foetomaternal histocompatibility in toxaemia of pregnancy" was summarized in three and a half pages, of which three tables and a figure comprised a major portion. Finally, the English of some of the papers is rather poor and the meaning occasionally obscure. It should also be mentioned that the title of the book is rather misleading, since many papers discuss the function and the properties of anti-antibodies which are neither of human origin nor directed against human $\gamma$-globulin.

The book, of course, contains some original and informative data; particularly interesting is the work of Speiser and collaborators on the transient nature of anti-Gm which appears during childhood. M. AdINOLFI 